Neuerscheinungen

Van den Hoonhaard, W. C.:

- Map Worlds - A History of Woman in Cartography

Wilfrid Laurier University Press, Waterloo, Ontario, 2013, $377 \mathrm{~S}$. s/w-Abb., $18 \times 23,5 \mathrm{~cm}, 49,00 \mathrm{f}$, ISBN 978-1-55458-932-6 (geb.); 978-1-55458-934-0 (epub.)

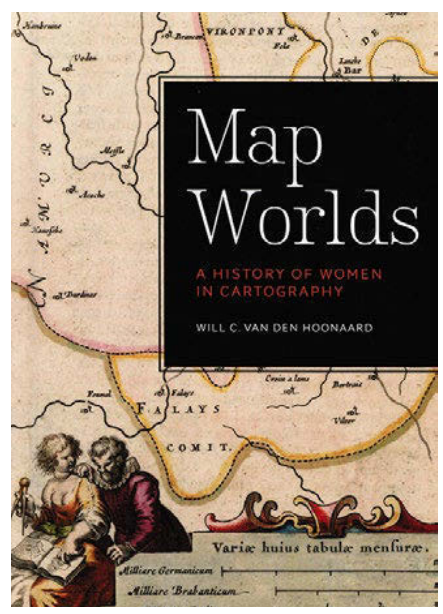

Staatsbibliothek zu Berlin ( $\mathrm{Hg}$. )

- Mercator-Hondius-Atlas Gerardi Mercatoris et I. Hondii Atlas Reprint nach der Ausgabe Amsterdam 1633

reprint Verlag Leipzig, Sonderausgabe 2014. 360 S. mit 165 doppelseitigen Karten, geb., 49,95 EUR [D]; ISBN 978-3-8262-3031-8

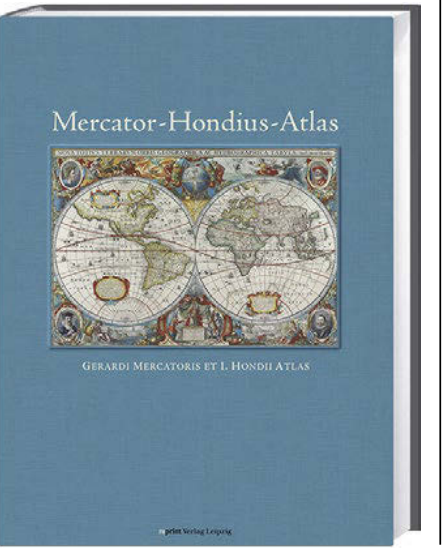

Kolbe, T., Bill, R., Donaubauer, A. (Hrsg).:

- Geoinformationssysteme 2014 Beiträge zur

\section{Münchner GI-Runde}

Wichmann, Heidelberg 2014, VIII, 256 S., Broschur, 48,00 EUR [D] ISBN 978-3-87907-537-9

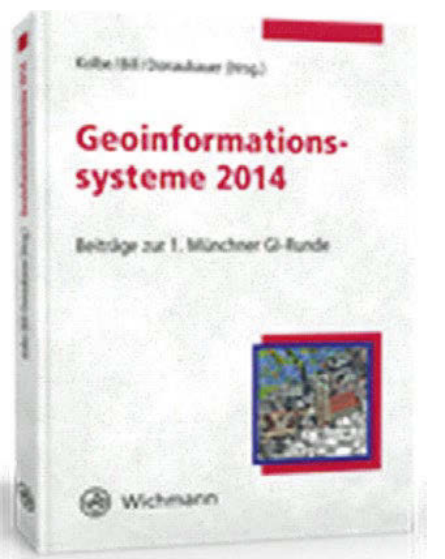

Historisch-topographischer Atlas schlesischer Städte 4 Tom/Band 4 :

- Nowa Sól/Neusalz.

Historyczno-topograficzny atlas miast ślaskich/ Historisch-topographischer Atlas schlesischer Städte

Herausgegeben von Peter Haslinger, Wolfgang Kreft, Grzegorz Strauchold und Rościsław Zerelik; bearbeitet von Hans-Jürgen Klink und Jolanta Rusinowska-Trojca; Marburg-Wrocław 2013, 52 S., 26 Karten, 63 Abb.

Einzelpreis EUR 15,- inkl. MwSt. zzgl. Versandkosten,

ISBN 978-3-87969-384-9

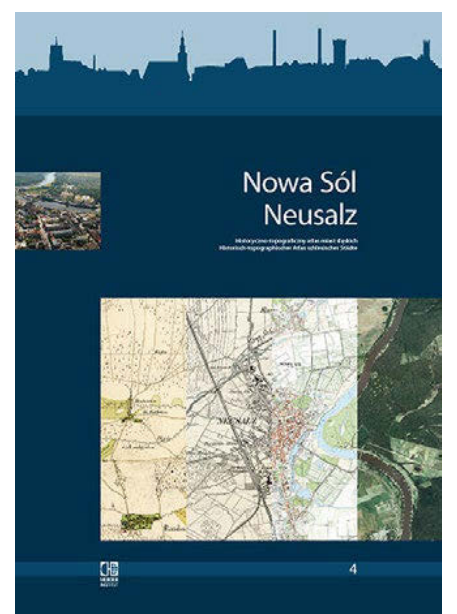

Geoinformation aktuell

\section{Business News}

\section{Mitteilungen aus Wirtschaft und Verwaltung}

\section{Fernerkundung Innovative Technologien für Katastrophenschutz- und Sicherheitsbehörden}

Mit einem Rahmenvertrag zwischen dem Bundesministerium des Innern und dem Deutschen Zentrum für Luft- und Raumfahrt e.V. (DLR) ist mit Beginn 2013 für Katastrophen- und Sicherheitsbehörden ein einfacher Zugang zu Fernerkundungsdaten geschaffen worden.

Mit diesem Vertrag entstand im Deutschen Fernerkundungsdatenzentrum (DFD) des DLR das Zentrum für Satellitengestützte Kriseninformation (ZKI). Mit potentiellen Nutzern haben Geowissenschaftler des DLR Kriseninformationsprodukte spezifiziert, die den unterschiedlichen Informationsbedarf bei großen Unglücksfällen und Katastrophen wie Hochwasser, Waldbrände, Erdrutsche, etc. decken sollen.

Zusammen mit Mitarbeitern der Sicherheitsbehörden entwickelte das ZKI weitere Produkte speziell für deren Bedarf wie z. B. für Massenveranstaltungen.

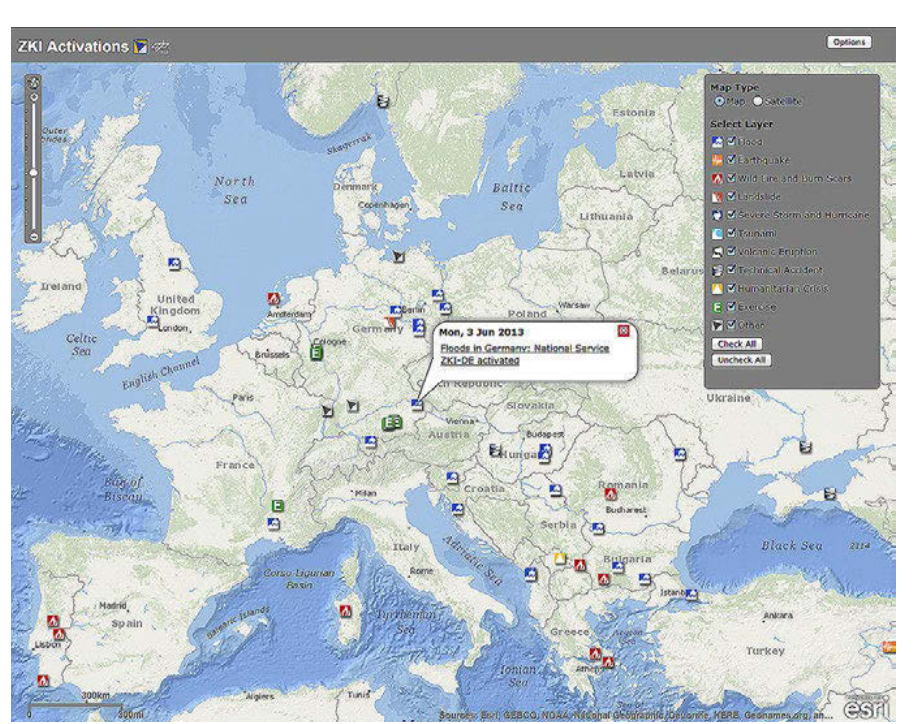

Webmap des Zentrums für Satellitengestützte Kriseninformation mit vergangenen Aktivierungsorten. @ DLR/ZKI 2014 serschutz in Deutschland hat das DLR eine erste Konzeptskizze für ein Hochwasserinformationssystem gefertigt. Ähnlich dem vom DLR entwickelten Tsunami-Warnsystem für Indonesien soll ein Hochwasserinformationssystem alle relevanten Daten zu Hochwasserprozessen, die jetzt schon bei verschiedenen Bundes- und Landesbehörden, bei führenden Großforschungseinrichtungen, verschiedenen Universitäten und Unternehmen vorliegen, zusammenführen. Ziel dieser Entwicklung soll auch sein, die Prävention durch Risikoanalysen auf der Basis von Simulationen in 3D-Modellen und die Steuerung der Katastrophenhilfe effektiver unterstützten zu können. Mit dem Aufbau einer Szenarien-Datenbank für Hochwasserlagen lassen sich die 